\title{
Effect of deprivation level on span of attention in a multi-dimension discrimination task'
}

\author{
JEROME S. COHEN, ${ }^{2}$ LAURENCE J. \\ STETTNER, and DONALD J. MICHAEL, \\ Wayne State University, Detroit, Mich. \\ 48202
}

Twelve male hooded rats were trained on a discrimination task in which two perfectly correlated cues (size and shape) were present. Half of the Ss were trained under moderate level of water deprivation (MOD group) while the other group was highly water-deprived (HI group). Not only did MOD Ss learn the task more quickly than HI Ss, but the former made fewer errors on tests utilizing only the shape cues. This stuly supports the hypothesis that span of attention is inversely related to drive level.

According to Tolman (1948) span of attention of an organism is inversely related to drive level. An experiment by Bruner, Matter, \& Papanek (1956) supports this notion. In their study lower water-deprived rats picked up and utilized concomitant position cues when brightness cues were removed in an alternation task with four choice points. Highly deprived Ss, however, were unable to perform the alternating sequence when brightness cues had been removed. The authors failed to determine whether the position cues were internal or external stimuli.

The present study attempts to establish the differences in span of attention by using two specific external cue dimensions, shape and size. Work by Sutherland \& Holgate (1966) and Hughes \& North (1959) show that rats can pick up information about two partially or completely correlated external cue dimensions such as orientation (horizontal vs vertical stripe) and brightness (black vs grey) or brightness and shape, respectively. The present study uses the cue dimensions size and shape. Ss are placed on either a moderate or high deprivation schedule and are required to learn a discrimination of small circle vs large triangle. After reaching learning criterion $S s$ should be able to perform above chance on only one dimension while less deprived $S$ s should be able to utilize either dimension in performing the task.

\section{SUBJECTS}

Twelve male hooded rats, Marland strain, approximately 90 days old at time of water taming, were used. Half of the Ss were randomly placed in either the high water-deprivation group $(\mathrm{HI})$ or the noderate deprivation group (MOD).

\section{APPARATUS}

A discrimination box, $29.0 \times 15.0 \times 9.5 \mathrm{in}$., was used. The apparatus was divided into a decision chamber, $18.5 \times 15.0$ in., and two goal chambers, $10 \times 7$ in. Entry was gained into the decision chamber through a covered start box, $6 \times 4 \times 4$ in., at floor level midway on the wall opposite the discriminanda. A manually operated guillotine door could be lifted to expose $S$ to the decision chamber. Access to reinforcement was through a doorway, $4.5 \times 3.5$ in.. to each of the goal chambers. Each doorway was 1.5 in. from each other and 3 in. from its nearest wall. Interchangeable stimulus doors could be attached behind each doorway. Except for the white discrimination stimuli, all interiors were painted flat black. The only source of illumination was provided by a 75-W incandescent bulb situated over the entrance to the decision chamber.

\section{PROCEDURE}

Pretraining

All Ss were maintained on a 6 -h water schedule during $24 \mathrm{~h}$ for 12 days. Each $\mathrm{S}$ was handled $5 \mathrm{~min}$ per day for 3 days while allowed to drink a $10 \%$ sucrose solution. During the next 3 days, Ss were allowed 5 -min free exploration of the discrimination apparatus and allowed to drink in the goal chamber. During this time $S s$ were placed in the goal chambers to give them equal experience with each chamber. For the next 3 days black doors were placed behind the doorways and $\mathrm{S}$ had to push them open to secure sucrose water reinforcement. Each $S$ received 5 min per day of such training and all Ss readily learned this task. The last 3 days were spent in attempting to break position preferences $S$ might have developed during the previous 6 days of pretraining. Each $S$ was presented 12 spaced trials per day. Each $S$ received one trial and then was replaced back in its home cage while another $S$ was removed from its home cage and given a trial. Since six Ss were run like this at a time, each $S$ experienced approximately 4-min intertrial intervals. This procedure was continued throughout the study. On each trial one door was locked and the othe closed door unlocked. A random-position sequence developed by Fellows (1967) was used in this and all subsequent phases of the procedure. At this stage of training and throughout the study $S$ was allowed a $10-\mathrm{sec}$ drink of $10 \%$ sucrose solution on each trial

Discrimination Training

Two deprivation groups of six Ss each were maintained on either a highdeprivation schedule (HI group) of $0.5 \cdot \mathrm{h}$ water per $24 \mathrm{~h}$ or were continued on the previous moderate schedule (MOD group) of $6 \mathrm{~h}$ ad lib drinking per $24 \mathrm{~h}$. In this phase and in the testing phase $S$ s were presented black doors with white stimuli at tached on the midline of each door, $1 \mathrm{in}$. from the floor of the apparatus. Each stimulus was constructed from white poster board $1 \mathrm{~mm}$ in thickness. In the discrimination training $S$ was faced with a choice between a small circle (1.00 in. diam) or a large equilateral triangle (2.25 in. high). For half of the Ss in each deprivation group the small circle was the correct choice leading to re inforcement. The other half of the group had to choose the large triangle to receive reinforcement. Each $S$ received in this and the testing phase 12 corrected trials per day. A trial consisted of the number of runs made until $S$ chose the correct door. $\mathrm{S}$ was replaced in the start box when it had made an error. An error was considered to have been made only when S pushed on or touched the incorrect door with its nose. Since each door when locked could budge about 0.25 in.. observing mistakes was not difficult. A correct response constituted either direct running to the correct door or switching over to that door after the incorrect door had been approached but not touched. S reached criterion for learning when it made two or less errors within 24 consecutive trials.

\section{Testing}

After $S$ had reached criterion it was tested in order to determine what particular dimensions, size or shape, it utilized in solving the problem. Ss were presented 72 discrimination trials ( 12 trials per day). Every third trial during a daily run was a test trial while the rest of the trials were of the same type as in the previous training phase.

Table 1

Mean Errors for Each Deprivation Group on Size and Shape Tasks

\begin{tabular}{llllllll}
$\begin{array}{c}\text { Deprivation } \\
\text { Group }\end{array}$ & A & $\begin{array}{c}\text { Size } \\
\text { B }\end{array}$ & $\begin{array}{c}\text { Tasks } \\
\text { Combined }\end{array}$ & C & $\begin{array}{c}\text { Shape } \\
\text { D }\end{array}$ & $\begin{array}{c}\text { Tasks } \\
\text { Combined }\end{array}$ \\
\hline HI & 0.17 & 1.17 & 1.33 & 3.67 & 3.33 & 7.00 \\
MOD & 1.00 & 1.00 & 2.00 & 3.00 & 2.17 & 5.17 \\
\hline
\end{tabular}


During a test trial both stimulus dours were unlocked and $S$ could receive reinforcement by entering through either one. Four different types of stimulus pairs were used to test learning about the two different cue dimensions. For the size dimension: Pair $\mathbf{A}$, large equilateral triangle (2.25 in. high) vs small equilateral triangle ( $1.00 \mathrm{in.} \mathrm{high),} \mathrm{and}$ Pair B. large circle (2.25 in. diam) vs small circle $(1.00 \mathrm{in}$. diam) were used. For the shape dimension: Pair $C$, small triangle vs small circle, and Pair D, large triangle vs large circle, were the tasks involved. Each pair of stimuli was presented six times. i.e., once during each of the 6 testing days. Pair schedules for the 6 days were as follows for each S: ACDB. DBAC, CABD. BDCA, CABD. DBAC. An error on a test trial was considered to have been made if $S$ chose the opposite size or shape (depending on the test trial) to which $S$ had been originally trained for reinforcement.

\section{RESULTS}

MOD Ss learned the original discrimination task in a mean of 13 trial blocks while HI Ss required a mean of 20 trial blocks to master this task. Thus MOD Ss learned significantly faster than $\mathrm{HI}$ Ss $(t=2.80$, $\mathrm{df}=10 . \mathrm{p}<.01)$.

Analysis of variance of results from the testing phase. as represented in Table 1 , revealed that significantly fewer errors were made on size-cue tasks combined than on shape-cue tasks combined ( $F=64.67$. df $=1 / 10 . p<.01$ ). Comparisons of simple effects showed that the above effect was evident well bey ond the .01 critical level for each deprivation group.

Even though the shape dimension was more difficult for both $\mathrm{HI}$ and MOD Ss to acquire. MOD Ss made significantly fewer errors on the shape tasks than HI Ss $(\mathrm{p}<.01)$. The groups did not differ significantly in errors on the easier size dimension. These individual comparisuns help to explain the trend for MOD Ss to make generally fewer errors than $\mathrm{HI}$ Ss $(F=3.36$. df $=1 / 10, .05<p<.10)$, and the significant task deprivation interaction $(F=5.17 . \mathrm{df}=1 / 10 . \mathrm{p}<.05)$.

A further analy sis was done to assess the effects of drive level upon each particular task. Only for Task D (large circle vs large triangle) was there a trend $(.05<\mathrm{p}<.10)$ for MOD Ss to make fewer errors than $\mathrm{HI}$ Ss The difficulty of the shape Task C (small circle vs small triangle) may have knocked out any attention differences attributable to drive level.

The above results seem to indicate that MOD Ss were able to utilize shape dimension cues better than HI Ss. This seems particularly so for Task D. However, if both groups had made $50 \%$ or more errors (three or more errors) on the shape tasks, then MOD Ss could not be said to have acquired more information about the relevance of this cue even though they made fewer errors than HI Ss. On Task D, for example, five MOD Ss made two or less errors while only two HI Ss made less than $50 \%$ errors. This difference represents a trend $(\mathrm{p}=.11)$ in the predicted direction (Fisher's exact probability test). Neither group appeared to have acquired any information concerning Task C (small triangle vs small circle). Except for two MOD Ss, all Ss made three or more ( $50 \%$ or more) errors.

\section{CONCLUSION AND DISCUSSION}

Not only did MOD Ss learn two multicue discrimination tasks in significantly fewer trials, but made fewer errors on the shape dimension than HI Ss. It should be noted, however, that the easier dimension for both groups was the size dimension. The shape dimension proved difficult for both groups and only when the stimuli were of apparently larger size could the MOD Ss perform better than HI Ss. Even so, this amounted to only a trend in the predicted direction. Other less difficult cue dimensions should bring out these differences even more sharply. The present study, however, indicates that lower drive Ss acquired more information about some aspect of the more difficult shape dimension. These results support Tolman's contention that span of attention is inversely related to drive level.

The span of attention concept did not predict rate of acquisition of the original discrimination task. HI Ss required significantly more trials to reach learning criterion. Eisman, Asimow, \& Maltzman (1950) did not find acquisition diffirences between their drive level groups in a brightness discrimination. Two possibilities can be offered to explain the differences between these two studies. The cue dimension of brightness in the earlier study may have been easier to pick up than size dimension, so that possible attention differences due to drive were not evident in the earlier work. Another possibility is that the multicue situation may have been a more confusing task than if only one dimension had been presented to HI Ss.

The present study offers a technique to investigate differential information acquisition as a function of motivation. Further work in this field should determine more precisely the amount of information capable of being acquired under present levels of drive and the amount of retention and utilization of such information under later drive conditions.

\section{REFERENCES}

BRUNER, J. S., MATTER, J., \& PAPANEK, M.L. Breadth of learning as function of drive and mechanization. Psychological Review, 1955, 62, 1-10.

EISMAN, E, ASIMOW, A., \& MALTZMAN, 1. Habit strength as a function of drive in a brightness discrimination problem. Journal of Experimental Psychology, 1956, 51, 58-64.

FELLOWS, B. Chance stimilus sequences for discrimination tasks, Psychological Bulletin, 1967, 67,87-92.

HUGHES, C. L.. \& NORTH, A. Effect of introducing a partial correlation between a critical cue and a previously irrelevant cue. Joumal of Comparative \& Physiological Psycholory, 1959. 52.126-128.

SLTHE RLAND, N. S..\& HOLG iTE, V. Two-cue discrimination leaming in rats. Joumal of Comparative \& Physiological Psychology, 1966. 61. 198-207.

TOLMAN, E. C. Cognitive maps in rats and men. Psychological Review, 1948, 55, 189-208. NOTIS

1. The research was supported by research grants to J.S. Cohen from the Graduate School of Wayne State University and irom the National Institute of Health (NIH I R-(0) $051-02$, BWS-10). The authors wish to thank S. Lachman and A. Smith for their valuable assistance and advice.

2. Now at the Eniversity of Windsor, Windsor, Ontario. 